Uludag Univ. J. Fac. Vet. Med.

32 (2013), 1: 47-52

\title{
Sığırlarda Respiratorik Distrese ve Asfeksiye Yol Açan Önemli Zehirlenmeler
}

\author{
Gülşah AKGÜL* $\quad$ Zafer MECİOĞLU** \\ Geliş Tarihi: 23.09 .2013 \\ Kabul Tarihi: 24.10.2013
}

Sezgin ŞENTÜRK ${ }^{* * *}$

Özet: Sunulan derlemede, sığırlarda akut solunum stresi ve asfeksiye neden olan $\mathrm{NO}_{2}, \mathrm{H}_{2} \mathrm{~S}$, 4-Ipomeanol, Organik Fosforlu İnsektisitler, Karbamatlar, Nitrit, Nitrat, Siyanür ve Arsenik gibi zehirlenmelerin etiyolojileri, klinik ve başlıca patolojik bulguları ile tedavileri hakkında bilgiler verilmiştir.

Anahtar Kelimeler: Sığır zehirlenmesi, solunum güçlüğü, asfeksi.

\section{Important Toxications of Cattle Causing Respiratory Distress and Asphexia}

\begin{abstract}
Presented review, summarizes the ethiological factors, clinical and pathological findings and treatment options of some of the important toxications characterised with acute respiratory distress and asphexia in cattle such as $\mathrm{NO}_{2}, \mathrm{H}_{2} \mathrm{~S}$, 4-Ipomeanol, Organic Phosphorus Pesticides, Carbamates, Nitrite, Nitrate, Ciyanide and Arsenic.
\end{abstract}

Key Words: Cattle poisining, respiratoric distress, asphexia.

\section{Nitrojen Dioksit $\left(\mathrm{NO}_{2}\right)$ Zehirlenmesi}

Nitrojen dioksit rahatsız edici keskin kokusu olan kahverengimsi bir gazdır. Özellikle misır silajı yüksek oranda nitrojen dioksit üretir ve silaj kapatıldıktan sonraki ilk 48 saat içerisinde çok yoğun oranda nitrojen dioksit meydana gelir ve 2-3 hafta bu tehlike devam eder ${ }^{8}$. .Nitrojen dioksit solunum yolu epitelyumlarında nitrous asit, nitrit okside, nitrat ve nitrite dönüşür. Bu oluşumlar tip-1 pnomösitlere ve silialarda toksik etki yaparak onların fonksiyonlarını bozarlar. Nitrit oksit hücresel y1kımlanmaya yol açar ve ayrica lokal immuniteyi ve makrofaj aktivitesini deprese eder, hemoglobine bağlanarak ilk 30 dakika içerisinde methemoglobinemi oluşmasına neden olarak hipoksiye katkı sağ$\operatorname{lar}^{26}$.

\section{Klinik Bulgular}

Etkilenen hayvanlarda taşipne, dispne, taşikardi, beden 1sısında artış, iştah ve süt veriminde azalma ve abdominal sanc1 belirtileri meydana gelmektedir. Ayrıca ağızda köpüklü salivasyon, boyun önde hirıltılı solunum ve bazı hayvanlarda deri altı anfizem oluşmaktadır. Nitrojen dioksitin mukozalarda yarattığ yona bağlı olarak konjektivitis meydana gelmektedir. İlk dönemlerde methemoglobin oluşumuna bağlı olarak hipokside artış ve mukozalarda siyanöz meydana gelmektedir. Kronik toksikasyonlarda kronik obsturiktif akciğer hastalığı ve enfektif pnomöniler oluşumları görülür ${ }^{8}$.

\footnotetext{
* Araş.Gör.U.Ü. Veteriner Fakültesi İç Hastalıkları A.B.D. gulsahdemir@uludag.edu.tr

** Araş.Gör.Dr. U.Ü. Veteriner Fakültesi İç Hastalıkları A.B.D.

*** Prof.Dr. U.Ü. Veteriner Fakültesi İç Hastalıkları A.B.D.
} 


\section{Otopsi Bulguları}

Otopsi bulgularında, üst solunum yollarında ve akciğer paranşiminde peteşiyel kanama odakları, trakheada köpüklü sekresyon ve akciğerlerde büyüme ve üzerlerinde kosta izleri görülebiliti ${ }^{38}$.

\section{Tedavi}

Hayvanların barınaklarında hava akımı sağlanmalıdır ve silaj çukurlarından uzak yerlerde barınmaları sağlanmalıdır. Tedavide dexamethasone, furosamide, asetilsistein uygulanmalıdır. Olası sekonder enfeksiyonlara karşı antibakteriyeller kullanılabilir ${ }^{17,38}$.

\section{Hidrojen Sülfür $\left(\mathrm{H}_{2} \mathrm{~S}\right)$ Zehirlenmesi}

Hayvan gübrelerinde hidrojen sülfür, amonyak, karbondioksit ve metan yoğun olarak açığa çıkan toksik gazlardır ${ }^{18}$.

Hidrojen sülfür, organik maddelerin fermantasyonu sırasında açığa çıkan çürük yumurta kokusu olan renksiz toksik gazdir ${ }^{31}$.

Nadiren rastlanılan bir zehirlenme türüdür ancak çok kalabalık ve gübresi uzaklaştırılmayan havasız ahırlarda bulunan ruminantlarda veya mağaralar ve kimya endüstrisi atık bölümlerinde uzun süre barındırılan hayvanlarda meydana gelebilir ${ }^{28,35}$.

Solunum havasinda \%0,1-0,2 konsantrasyonu oranında hidrojen sülfür bulunmasında ani ölümler meydana gelebilir. Ölüm nedeni hidrojen sülfürün oksihemoglobin seviyesini bask1laması ve stokroma bağlanması sonucu hücresel hipoksi ile ilişkilidir ${ }^{38}$.

\section{Klinik Bulgular}

Klinik bulgular arasında taşikardi, taşipne, dispnei ve konjektivitis yer alır. İlerleyen dönemlerde konvulsiyonlar ve bilinç kaybı meydana gelebilir. Çok yoğun maruz kalmada kardiyopulmoner arrest ve ölüm şekillenebilir. Ayrıca mukozalar siyanöz hal alır ve pulmoner hipertansiyon gelişebilir ${ }^{25}$.

\section{Otopsi Bulguları}

Redükte hemoglobin yüksekliğine ve methemoglobine bağlı olarak kan daha koyu renktedir. Asfeksiden dolayı trekheada köpüklü sıvı oluşmaktadır. Tipik patolojik değişimler gelişmediğinden doku ve kan örneklerinin sistemik toksikolojik ve histopatolojik içelemeleri yapılmalıdır ${ }^{38}$.

\section{Tedavi}

Sodyum nitrat verilerek methemoglobin oluşturukması tedavi için yarar sağlayabilir.
Furosamide uygulamas1 8 saat ara ile yapılabi$\operatorname{lir}^{21}$.

\section{Küflü Tatlı Patates (4-Ipomeanol) Zehirlenmesi}

Fusarium solani mantarının bulunduğu küflü patateslerde üretilen furanoterpenoid toksininin alınmasını takiben meydana gelen zehirlenmedir ${ }^{8}$.

Tatlı patates üzerinde Fusarium solani ürediği zaman patates hepatotoksik etkili olan 4hidroksimyporon üretir ve bu madde mantarlar tarafindan şiddetli pnomötoksik etkili olan 4ipomeanola dönüştürülür ve bu madde de hayvanlarda akciğerlere yönelik doğal bir toksik maddedir. Toksik maddeyi kapsayan patateslerin hayvanlar tarafindan yenmesi sonucu rumenden emilen madde kan dolaşımı ile akciğerlere ulaşır ve bronşiol epitelyumlarda tip-1 pnomösitlerde sitokrom p-450 oksidaz sistemi tarafindan interselüler proteinlere yüksek bağlanma affinitesi olan reaktif metabolitlere dönüşür. Bu reaktif metabolitler akciğerlerde şiddetli pulmoner ödem, hemoraji, alveolar hiperplasi ve anfizem oluşumuna neden olur ${ }^{38}$.

\section{Klinik Bulgular}

Zehirlenmelerde alınan toksin miktarına bağlı olar taşipne, polipne, taşikardi, dispne, hırıltılı ekspirasyon, solunun güçlüğü ve derinden gelen öksürük ve auskultasyonda çıtırtılı harhara ve sürtünme sesi duyulmaktadır ${ }^{3}$.

\section{Otopsi Bulguları}

Akciğerler büyük ve serttir. Loblar koyu kırmızı renktedir. Hemoraji alanları, sarı jelatinöz ödem sıvısı ve anfizem alanları görülebilir. Histopatolojik incelemeler sonucunda miks interstitiel hücre infiltrasyonu, alveolar epitelyumiyel hiperplazi ve hyalin membranlar tespit edilebilir ${ }^{8}$.

\section{Tedavi}

Tedavi de aktif kömür ağızdan içirilebilir. Furosamide ve fluneksin meglumin uygulaması denenebilir ${ }^{38}$.

\section{Organofosforlu İnsektisit (OFI) ve Karbamat Zehirlenmesi}

Organik fosfor zehirlenmeleri ciddi klinik sonuçlara neden olabilir. OFI ve karbamat bileşikleri ile zehirlenmeler saha şartlarında çok sik rastlanılan zehirlenme türüdür. Muskurinik etkilerine bağlı şiddetli akciğer ödemi, brokospazm, pulmoner hipertansiyon ve nikotonik etkilerine bağlı olarak solunum kasla- 
rının paralizine yol açmaları nedeni ile önemli solunum sistemi yansımalarına neden olurlar ${ }^{8}$.

OFI'leri oluşturan önemli etkenler metil parathion, diazinoni, dichlorvos, malathion, bromophos ve chlorpyrifos'dur. Aldicarb, carbofuran, carbosulfan, methomyl, dioxicarb ve carbarly ise önemli karbamatlardır.

$\mathrm{Bu}$ zehirlenmeler genellikle oral yol, inhalasyon veya deri teması ile OFİ maruziyeti sonucu ortaya çıkmaktadır ${ }^{6}$. OFI'ler, merkezi sinir sisteminde ve eritrositlerde bulunan asetilkolinesteraz enzimi ile plazmada bulunan butirilkolinesteraz enziminin aktif bölgesindeki fosfat radikallerine kovalent bağla bağlanarak bu enzimleri geri dönüşümsüz olarak inhibe ederler ${ }^{3}$. $\mathrm{Bu}$ enzimlerin inhibisyonu sonucunda hidrolize olmayan ve biriken asetilkolin, kolinerjik reseptörleri aşırı bir şekilde uyararak zehirlenme belirtilerinin ortaya çıkmasına neden olur ${ }^{39}$.

Etkilenen hayvanlarda köpüklü salivasyon, gözyaşı ve nasal akıntı, taşipne, dispne, öksürük ve hırıltılı solunun meydana gelebilir. Bunların yanında sik olarak idrar yapma pozisyonu alma, kaslarda sertlik, yürürken sendeleme, meterismus, tremorlar, konvulsiyonlar ve pupillalarda daralma gelişebilirr ${ }^{26}$.

\section{Otopsi Bulguları}

Akciğer paranşiminde şiddetli konjesyon, alveollerde ve bronşlarda yoğun köpüklü sekrekyon gözlenebilir ${ }^{4}$.

\section{Tedavi}

Tedavide atropin uygulanması endikedir. Ağızdan aktif kömür içirilebilir ve eğer bulaşma kaynağı deri yoluyla ise etkilenen hayvanın bol bol yıkanması önerilmektedir. Kesinlikle yağl1 sürgüt verilmemelidir ${ }^{38}$.

\section{Nitrat-Nitrit Zehirlenmesi}

Nitrat ve nitrit; katkı maddesi veya kontaminantlar şeklinde doğada yaygın olarak bulunmaktadır ${ }^{20}$. Yulaf otu, arpa, buğday, çavdar gibi tahılların körpe otları ve sudan otu, misır, sorgum türleri, kolza, tatlı yonca, havuç, şalgam, mısır, keven ve özelikle pancar yaprağı önemli miktarda nitrata sahip bitkilerdir. Tarlalarda kullanılan herbisitlerin nitratın bitkilere bağlanma oranını artırır. Azot içeren sanayi atık suları, suni gübreler ve bozulmaya uğramış organik maddeler nitrat ve nitritin en önemli kaynağını oluşturmaktadır ${ }^{1,37}$.

Rasyonda enerji/protein dengesizliği ve alınan yemlerde $\% 1,5$ 'dan daha fazla nitrat bu- lunması birkaç saat içerisinde zehirlenme belirtilerinin ortaya çıkmasına yol açar ${ }^{38}$.

Nitrat; insan ve hayvanlar tarafindan çeşitli gıdalarla alındıktan sonra midede mikroorganizmaların etkisiyle nitrit ve amonyağa indirgenir. Nitratın fazlası midede biriken nitrit ve amonyak ile birlikte emilerek kana karışır. Nitrit, kanda bulunan oksihemoglobini methemoglobine çevirir. Methemoglobin oksijen taşıyamaz ve bu şekilde nitrit zehirlenmesi oluşur ${ }^{30}$. Methemglobinin oksijen taşıma kapasitesi yoktur ve oluşan methemoglobinin düzeyine bağl1 olarak değişen derecelerde hipoksi hatta çok yoğun alımlarda anoksi ve ölüm şekillenir ${ }^{38}$.

Hemoglobinin \%20'si methemoglobine dönüştüğünde zehirlenme belirtileri ortaya çıkar bu belirtiler solunum sayısının artması, dispne, taşikardi, zayıf nabızdır ${ }^{38}$. Auskultasyonda sertleşmiş veziküler ve bronşiyel sesler duyulmktadır. Ve mukozalar başlangıçta siyanotik kısa bir süre sonra kahverengi-grimtrak renk alırlar. Solunum stresi bulgularının dişında etkilenen hayvanlarda ishal, sanc1, kaslarda titreme, sallantılı yürüyüss, ataksi, sık sık damla damla idrar yapma ve salivasyon gözlemlenir. Hayvanın kanı çikolata rengindedir. Şiddetli hipoksi sonucu son dönemde yerde yatma, konvulsiyonlar ve ölüm şekillenebilir. Kronik zehirlenmelerde solunum sistemi bulguları dikkati çekmez aksine hipovitaminöz A ve bazı dokuların iyi beslenmemesinden kaynaklı ortaya çıkan semptomlar dikkati çeker ${ }^{24,32}$.

Klinik tanıda bize yardımcı olan en önemli testlerden biri idrar muayenesinde idrar stripinde aşırı nitrat varlığıdır. Ve diphenylamine testi ile nitrit düzeyi belirlenir. Kanda methemoglabin düzeyi yüksektir ${ }^{23}$.

\section{Tedavi}

Akut zehirlenmelerde spesifik antitod metilen mavisidir ${ }^{3}$. Kronik zehirlenmelerde oluşan semptomlar genellikle irreversibil bozukluklardır bu yüzden spesifik tedavisi söz konusu değildir ama hayvanların rasyonlarını değiştirmek ve nitratça zengin yemleri kısıtlamaya gidilmesi gerekmektedir ${ }^{7}$.

\section{Siyanür Zehirlenmesi}

Siyanür canlıların çeşitli kaynaklardan aldıkları zehirli bir maddedir ${ }^{15}$. Hidrosiyanik asit $(\mathrm{HCN})$ renksiz acı badem kokulu, uçucu bir gazdir ${ }^{2}$.

Siyanür gübre, tekstil, boya sanayisinde, fare mücadelesinde ve tarım ilacı olarak kullanılmaktadır ayrıca kiraz, şeftali, erik ve acı ba- 
dem de bulunmaktadır. Siyanürler protoplazmik bir zehirdir ${ }^{38}$.Vücuda değişik yollarla giren siyanürlü bileşikler histotoksik hipoksinin sebep olduğu belirtilere ve ölüme yol açar ${ }^{5}$.

Sığırlarda hidrosiyanik asit $(\mathrm{HCN})$ zehirlenmelerinin büyük çoğunluğu, siyanojenik glikozitler içeren bitkilerin yenmesi sonucunda meydana gelir. Siyanojenik glikozitler içeren 120 den fazla bitki türleri vardır ${ }^{38}$. Fï̆, burçak, sorgum, acı badem gibi siyanojenik glikozit içeren bitkilerin hayvanlar tarafindan yenilmesi; sodyum nitroprussid ve amigdalin içeren Laetrile gibi ilaçların kullanılması sonucunda vücutta bol miktarda HCN açığa çıkar ${ }^{29,33,34}$.

Glikozitler bitkilerin böcek ve sümüklülere karşı savunma olușturmak için kendilerinin ürettikleri maddelerdir. $\mathrm{HCN}$ sığırlarda minimum lethal dozu, glikozid halinda alındıklarında $2 \mathrm{mg} / \mathrm{kg} \mathrm{dir}{ }^{36}$. Bitkiler $200 \mathrm{ppm}$ veya daha fazla $\mathrm{HCN}$ içermeleri durumunda toksik kabul edilirler ${ }^{13,17,27}$

Bitkilerin hızlı büyüdüğü kuraklı sonrası dönemler, toprakta azotun fazla, fosforun düşük miktarda olması gibi faktörler bitkilerde glikozitlerin yüksek konsantrasyon da olmasina neden olur. Rumen ve abomasum'un pH'inın zehirlenme ile ilişkisi vardır, yüksek $\mathrm{pH}$ değeri zehirlenme olasılığını artırmaktadır ${ }^{9-12}$.

Akut zehirlenmelerde siyanür, sitokrom oksidaz enzimini inhibe ederek hücresel solunumu baskılar ve dokularda anoksiye neden olur. Oksijen kanda tutulur. Eğer zehirlenme uzun sürerse kanın rengi oksijen alımı kısıtlandığ1 için koyulaşır. Siyanür zehirlenmesi, kalp yetmezliği ve histotoksik anoksiye bağlı olarak serebral anoksiye neden olur. Sorgum içeren meralarda otlayan ineklerden doğan buzağılarda sinir hasarına bağlı olarak artrogrifozis şekillenebilir ${ }^{38}$.

\section{Klinik Bulgular}

Zehirlenen hayvanlar çok uzun süre yaşamadan genellikle 1-2 saat içinde ölüm gerçekleşir. Çoğu akut vakalarda hayvanlar bitkilerin yenmesinden sonra 2-3 dakika içerisinde ölürler. Etkilenen hayvanlar da dispne, huzursuzluk, tökezleme, tremorlar, inleme, terminal klonik konvülziyonlar ve opistotonus gözlenen klinik bulgulardır. Pupillalarda dilatasyon ve nistagmus ölüme yakın zamanda mukozalar siyanotik hal alır ve hipersalivasyon ve kusma gözlemlenebilir. Kronik zehirlenmelerde ise sorgum tüketen sığırların yavrularında artrogrifozis gözlenebilir. Ve bazı durumlarda myelomalazi şekillenebilir ve bu durumda da hayvan idrarını tu- tamaz, arka ekstremitelerde inkoordinasyon ataksi, başı sallama ve ayağa kalkamama mevcuttur $^{17}$.

Hastalık çok şiddetli seyrettiği için, etkilenen hayvanlarda çoğu zaman klinik bulgu gözlemlenemeden ölüm şekillenmektedir. Siyanhidrik asitten ölümünü araştırmk için pikrat testi yapılmaktadır. Diğer bir yöntem ise 1 damla mide sıvısı ile 1 damla kan karıştırılır ve oluşan renk kırmızı-turuncu ise siyanür zehirlenmesi olduğu düşünülür ${ }^{14}$.

\section{Otopsi Bulguları}

Ölüm katılığının erkenden şekillenmektedir, kan oksijenin dokular tarafından alınamaması nedeniyle kırmızı renkte görülebilmektedir ve ağız ve mide de kırmızı renk oluşmaktadır. Rumen ve iç organlarda acı badem kokusu duyulmaktadır. Her olguda subendokardiyal ve subperikardiyal kanamalar meydana gelmekte$\operatorname{dir}^{3}$.

\section{Tedavi}

Sağaltıma genellikle çok geç kalınmış olunur çoğu vaka ölümle sonuçlanmaktadır. Ancak tedavide ilk yapılması gereken damar içi yolla sodyum nitrat ve sodyum tiyosülfat uygulamasidır $^{3,17}$.

\section{Arsenik Zehirlenmesi}

Arsenik hem hayvan sağlı̆̆ açısından hem insan sağlığı açısından oldukça önem taş1maktadır. Bunun başlıca nedenlerinden birisi bu elementin doğada yaygın olarak bulunması diğeri de endüstride, hekimlikte ve zirai mücadele alanlarında kullanılan ilaç ve benzeri preparatların yapımında etkin madde olarak geniş çapta kullanılmasıdır ${ }^{8}$. Arsenik insektisit, herbisid filorosid, rodentisit akşap koruyucu olarak kullanılmaktadır ve arsenik asid, arsenik triklorür, arsenik trioksit, bakır arseniyat, kurşun öarseniyat, sodyum arseniyat bileşikleride cam ve boya sanayisinde kullanılmaktadır ${ }^{24}$.

Arsenik doku enzimlerini sulfhydril gruplarını bağlar hücrelerde oksidatif metabolizmayı bozarak nekroza yol açmaktadır. Tüm dokular arseniğe karşı duyarlı olmasına karşın, barsak, mide duvarı, karaciğer, böbrek, dalak, akciğer gibi organlar toksikasyondan daha fazla etkilenirler. Kronik zehirlenmelerde az miktarda sürekli alınan arsenik, karaciğer, böbrek, sindirim sistemi organları, epidermis, dalak ve akciğerlerde birikerek yeterli düzeye ulaştığında klinik bulgulara neden olmaktadir ${ }^{16,19,22}$. 


\section{Klinik Bulgular}

Akut zehirlenmelerde ilk bulgu zehrin alınmasından 20-50 saat sonra ortaya çıkmaktadır. Huzursuzluk, taşipne, abdominal ağrı, solunum gülcügü, hipersalivasyon, böğürme ve Rumen hareketlerinin durması gözlenmektedir. Ayrıca arsenik sindirim mukozalarını irkilttiği için şiddetli ishal ve dehidrasyon meydana gelmektedir ${ }^{3,38}$.

Kronik zehirlenmeler; hastanın zayıfladığ1, süt veriminin düştügü, tüylerinde matlık ve kırış1klık olduğu görülmektedir. İştahsızlık, indigesyon, göz kapaklarında ödem ve konjuktivitis ve dudaktan mermeye uzanan mukozal ülserasyonlar görülmektedir ${ }^{3,36,38}$.

\section{Otopsi Bulguları}

Gastrointestinal kanalda arsenik, kronik olgularda mide barsak mukozası altında kanamalar, karaciğer ve böbrekte yağlanmalar ve deride bronz renk oluşumu dikkati çekmekte$\operatorname{dir}^{8}$.

\section{Tedavi}

Zehirlenmede tavsiye edilebilecek antidotlar; sodium thiosulfate ve 2:3 dimercaptopropranalol'dur. Ağız yoluyla gerçekleşmiş ise zehrin alınması o zaman yağlı ve tuzlu sürgütler verilmelidir ${ }^{3,8}$.

\section{Kaynaklar}

1. Abercrombie F.N., Caskey, A.L., 1972. The Spectrofotometric Determination of Nitrate in Water. Res.Rep. Univ. III. Urbana-Champaign, 49, $1-79$.

2. Anonim 1970. Hydrogen Cyanide. Am. Industrial Hyg. Ass. J., 116-119.

3. Aytuğ, N., Alaçam, E., Görgül, S., 1989. sı̆̆ır Hastalıkları, Tüm vet Hayvancilık hizmetleri Yayını, İstanbul.

4. Baggot, J.D. 1977. Principles of drug disposition in domestic animals. In The Basis of Veterinary Clinical Pharmacology. Ed. Baggot, J.D. 1st edn, pp. 144-189. W.B. Saunders Co., Philadelphia.

5. Benz, F.W. et al. 1997. Biological Markers of Acute Acrylonitrile Intoxication in Rats as a Function of Dose and Time. Fundam. Appl. Toxicol. 36 (2), 141-148.

6. Berger, A.R., Schaumburg, H.H., 1996. Effect of occupational and environmental agents on the nervous system. In Bradley WG, Editor. Neurology in Clinical Practice. Boston: ButterworthHeinemann.p.1389-401.
7. Bromage, N.R., Shepherd, C.J., Roberts, J. 1988. Farming systems and husbandry practice. In: Shepherd CJ Bromage NR, eds. Intensive Fish Farming. Oxford: BSP Professional, pp.

8. Clarke, M.L., Harvey, D.G., Humphreys, D.J., 1981. Veterinary Toxicology. 2nd Ed. London: English Language Book Society and Bailliere, Tindal.

9. Conn, E.E., 1973 . Cyanogenic glycosides : Their occurence, biosynthesis and function. p. 55-63. In " Chronic Cassava Toxicitiy, Proceedings and İnterdisciblinary Narkshop ". London.

10. Conn, E.E., 1979 . Biosynthesis of cyanogenic glycosides. Naturwissenschaften, 66, 28-34.

11. Conn, E.E., 1980. Cyanogenic compounds. Ann. Rev. Plant. Physiol., 31, 433-451.

12. Conn, E.E., 1984. Compartmentation of secondary compounds. Annu. Proc. Phytochemical Soc. Europa, 24, 1-27.

13. 13.Coop, I.E. and Blakley, R.L., 1950 . The metabolism and toxicity of cyanides and cyanogenetic glycosides in sheep The N.2. Journal of science and Technology, 31, 44-58.

14. Cran, H.R., 1985. Suspected hydrocyanic acid poisoning in cattle. Veterinary.

15. Curry, S.C and Patrich, H.C.,1991. Lack of Evidence for a Percent Saturation Gap in Cyanide Poisoning. Ann. Emergency Med., 20 (5),523528.

16. Daghır, M.S. and Hariri, N.N. 1977. Determi11ation of total arsenic residi1esi11 cliieken eggs. 1. Agrie. Fd Chem., 25 (5),1009-1010.

17. Ellenhorn,M.J. and Barceloux,D.G.1988. 'Medical Toxicology. Puplished by Elseiver. London.

18. Feilden, N.E.H.,1982. Toxic gases from slurry. Farm Build Progr., 68,7-10.

19. Forth, W., HenschIer, D. und Rummel V. 1983. Algemeine und Spe:iel/e Plamıkologie 11nd Toxikologie. 4. Auflage. Wissenehaftsverlag Bihliographisehes Institüt, Mannheim.

20. Gray, J.I, Irvine, D.M., Kakuda, Y., 1979.Nitrates and N-nitrosamines in cheese. J. Food Prot., 42(3),263-272.

21.Hall, A.H., Rumack, B.H.,1997. Hydrogen sulfide poisoning: an antidotal role for sodium nitrite? Vet Hum Toxicol 39,152-154.

22. Hapke, H.J.,1988.Toxikologie fiir Veterinarmendi:iner. 2 neuocarbeirete auflage. Ferdinand enke verlag, Stuitgart.

23. Kaplan, A., Smith, C., Promnitz, D.A., Joffe, B.I, Seftel,H.C., 1990. Methaemoglobinemia due to accidental sodium nitrite poisoning. Report of 10 cases. S. Afr. Med. J., 77(6),300-301.

24. Kaya, S.,1995.Veteriner Klinik Toksikoloji. Medisan Yay. No: 21, Ankara. 
25. Lawson, G.H.K., McAllister, J.V.S.,1966.Toxic gases from slurry. Vet Rec., 79,274.

26. Menzer, R.E., Nelson, J.O.,1986. Water and soil pollutants In: Klaassen CD, Amdur MO, Doull J. eds. Casarett and Doull's Toxicology, 3rd ed. New York: Macmillan Publishing Company., 835-836

27. Newton, G.W., Schmdt, E.S., Lewis, J.P., Conn, E. and Lawrence, R., 1981. Amygdalin toxicity studies in rats predict chronic cyanide poisoning in humans. The Western Journal of Medicine., $134,97-103$.

28. Osweiler, G.D., Carson, T.L., Buck, W.B., Van Gelder, G.A.,1985.Toxic gases. In: Clinical and diagnostic veterinary toxicology,ed. Osweiler GD, Carson TL, Buck WB, van Gelder GA, 3rd ed., pp. 369-377. Kendall/Hunt, Dubuque, IA.

29. Padmaja ,G., 1995. Cyanide Detoxification in Cassava for Food and Feed Uses. Crit.Rev.Food Sci.Nutr., 35(4),299-339.

30. Parsons, M.L., 1978. Is the nitrate drinking water standard unnecessarily low. current research indivates that $1 \mathrm{t}$ is. Am. J.Med.Tech., 44, 952-954.

31. Pickrell, J.,1991. Hazards in confinement housing - gases anddusts in confined animal houses for swine, poultry, horses andhumans. Vet Hum Toxicol 33,32-39.
32. Pirinçci, İ., Keleştimur, H., 1987. Koyunlarda nitrat ve nitrit zehirlenmesi üzerine deneysel çalışmalar. DOĞA TU Vet. Hay. Derg., 11(3), 255265.

33. Pirinçci, İ. ve Tanyıldızı, S. 1994. Yemlerdeki HCN Düzeylerinin Belirlenmesi. Vet. Bil. Derg., 10 (1-2),84-89.

34. Prawat, H., Manidol,C., Ruchirawat, S., Prawat,U. and Tutiwachwut, P., 1995. Cyanogenic and Non-Cyanogenic Glycosides from Manihot Esculenta. Phytochemistry., 40(4),1176-1173.

35. Raisbeck, M.F., 1982. Is polioencephalomalacia associated with high-sulfate diets? J Am Vet Med Assoc., 180,1303-1305.

36. Salkowski , A. A. and Penney, D.G. 1994. Cyanide Poisoning in Animals and Humans: A Review. Vet. Hum. Toxicol., 36(5),455-466.

37. Scorer, R., 1974. Nitrogen: a problem of decreasing dilution. New Scientist, 62, 182-184.

38. Şentürk, S., 2011. Siğırların solunum sistemi hastalıkları. Özhan matbaası, Bursa.

39. Tunçok, Y., Hocaoğlu, A.N., 2006. Organofosfat11 insektisitlerle zehirlenme. Türkiye Klinikleri Cerrahi Tıp Bilimleri Acil Tıp Dergisi., 2,69-73. 